\title{
Data integration of 104 studies related with microRNA epigenetics revealed that miR-34 gene family is silenced by DNA methylation in the highest number of cancer types
}

\author{
Ziga Strmsek $^{1}$, Tanja Kunej ${ }^{1 *}$
}

${ }^{1}$ Department of Animal Science, Biotechnical Faculty, University of Ljubljana, Groblje 3, 1230, Domzale, Slovenia;

Corresponding author:

Tanja Kunej, PhD, Chair of Genetics, Animal Biotechnology and Immunology, Department of Animal Science, Biotechnical Faculty, University of Ljubljana, Groblje 3, Slovenia; Phone: 003891-320-3890; Fax: 003861-724-1005; Email: tanja.kunej@bf.uni-lj.si

Submitted: June 9, 2014; Revised: June 29, 2014; Accepted: June 29, 2014; Published: June 30, 2014; Citation: Ziga Strmsek, Tanja Kunej. Data integration of 104 studies related with microRNA epigenetics revealed that miR-34 gene family is silenced by DNA methylation in the highest number of cancer types. Discoveries 2014, Apr-Jun; 2(2): e18. DOI: 10.15190/d.2014.10

\section{ABSTRACT}

There is an increasing research interest regarding deregulation of microRNA (miRNA) expression by DNA methylation in cancer. The aim of this study was to integrate data from publications and identify miRNA genes shown to be silenced in the highest number of cancer types and thus facilitate biomarker and therapeutic development. We integrated relevant data from 104 published scientific articles. The following databases and bioinformatics tools were used for the analysis: miRBase, miRNA Genomic Viewer, MultAlin, miRNA SNiPer, TargetScan, Ensembl, MethPrimer, TarBase, miRecords, and ChIPBase. Among 2578 currently known human miRNAs and 158 known to be regulated by DNA methylation, miR-34 gene family (miR-34a, -34b, and $-34 c$ ) was shown to be silenced by DNA methylation in the highest number of cancer types. Consequently, we developed the miR-34 gene family regulatory atlas, consisting of its upstream regulators and downstream targets including transcription factor binding sites (TFBSs), CpG islands, genetic variability and overlapping QTL. MicroRNA-34 gene family has a potential as a cancer biomarker and target for epigenetic drugs. This potential has already been recognized as MRX34 is well into phase I studies. The developed miR-34 gene family regulatory atlas presented in this study provides a starting point for further analyses and could thus facilitate development of therapeutics.

Keywords: microRNA, miRNA, miR-34, DNA methylation, cancer

\section{INTRODUCTION}

MicroRNAs (miRNAs) are small non-coding RNAs, 19 - 25 nucleotides in length that regulate the translation and degradation of target mRNAs, and control approximately $60 \%$ of human genes ${ }^{1}$. By binding to the different target gene regions, i.e., 3'-untranslated region (3'-UTR), 5'-UTR, promoter, or coding sequences, they repress or activate translation (reviewed $\mathrm{in}^{2}$ ). The role of miRNA genes in cancer have been discovered early after 
their discovery because 1.) they are located on breaking-prone and cancer-associated genomic regions $^{3}, 2$.) they are involved in regulation of cell proliferation and apoptosis, ${ }^{4,5}$ and 3.) they were found to be deregulated in malignant tumors and tumor cell lines (oncomiR) in comparison with normal tissues ${ }^{6-8}$. MicroRNA genes can represent two opposing roles, either behaving as oncogenes or tumor suppressors (eg. miR-34 gene family) depending on the tissue type and presence of specific targets ${ }^{9}$. Importance of miRNAs in cancer has already been recognized as miRNA based drug MRX34 has already entered phase I studies ${ }^{10}$. Aberrant miRNA gene expression signatures (either up- or down-regulated) are characteristic in cancer cells $^{11}$. MicroRNA genes are regulated on various levels including epigenetic silencing with histone modification and/or DNA methylation of $\mathrm{CpG}$ islands that encompass or are located adjacent to miRNA genes. Moreover, the frequency of miRNA gene methylation and consequently the frequency of epigenetic regulation are at about one order of magnitude higher than that of the protein-encoding genes $^{12,13}$.

A lot of scientific articles independently reported aberrant DNA methylation of various miRNA genes in numerous cancer types. Most of these studies reported hypermethylation of upstream regions, thus resulting in downregulation of miRNA genes. Integrative review by Kunej et al. ${ }^{12}$, that included data from 45 studies published till 7/2010, revealed that miRNAs can be regulated by DNA methylation in only one cancer type, thus indicating that they are cancer type specific. On the other hand, miRNA can be silenced by DNA methylation in various cancer types, thus offering general cancer biomarkers. For example, miR-34a was reported to be silenced by DNA methylation in 12 cancer types ${ }^{12}$. Additionally, majority of scientific articles also used miR-127 as an experimental internal control in epigenetic studies of miRNA genes since it was the first miRNA shown to be epigenetically regulated in several cancer types ${ }^{14}$.

In this study we present further integration of data from publications published till 5/2014 which revealed that miR-34 gene family is regulated by DNA methylation in the highest number of cancer types - consequently this gene family was the focus of the current study. The results indicated that miR-34 family could be used as general cancer biomarker. However, the number of publications related to this topic is increasing and there is no systematic integration of publications and no clear data regarding biomarker and cure potential of the miR-34 gene family. Therefore the aim of this study was to: 1.) develop the catalog of cancer types associated with miR-34 gene family silencing by DNA methylation, 2.) create the miR34 gene family regulatory atlas and 3 .) discuss miR34 gene family's therapeutic potential and thus facilitate biomarker and therapeutic development.

\section{MATERIALS AND METHODS}

We reviewed literature published from 2006 to 5/2014 searching for publications through PubMed using key phrases: microRNA (miRNA), DNA methylation, $\mathrm{CpG}$ island, cancer, oncogene, epigenetics. Genomic locations and sequences of miR-34 gene family were obtained from miRBase ${ }^{15}$, release 20, June 2013. Visualization of genomic location of miRNA and quantitative trait locus (QTL) was performed using miRNA Genomic Viewer (http://www.integratomics-time.com/ miRNA-genomic-viewer/). Sequences of $2 \mathrm{~kb}$ upstream of miR-34 family genes and singlenucleotide polymorphisms (SNPs) were obtained from Ensembl (release 70 (1/2013)). CpG island analysis was performed using MethPrimer ${ }^{16}$ tool using the default parameters: window size $>100$, observed/expected $>0.6$, GC percent $>50 \%$ ). Mature miRNA seed regions and SNPs were determined using miRNA SNiPer $3.0^{17,18}$ and TargetScan ${ }^{19}$ (release 6.2). Analysis of transcription factor binding sites (TFBSs) was performed using ChIPBase $^{20}$ (parameters: hg19, all transcription factors, $5 \mathrm{~kb}$ upstream). Experimentally validated targets were obtained from TarBase ${ }^{21}$ (version 6.0) and miRecords ${ }^{22}$ databases and published literature. Alignments of pre-miRNA sequences were performed using MultAlin tool ${ }^{23}$.

\section{RESULTS}

In this study we performed literature mining to determine miRNAs that were most frequently showed to be deregulated by epigenetic mechanisms therefore having the potential for general cancer biomarkers and therapeutic targets. The results revealed that from all 2578 currently 


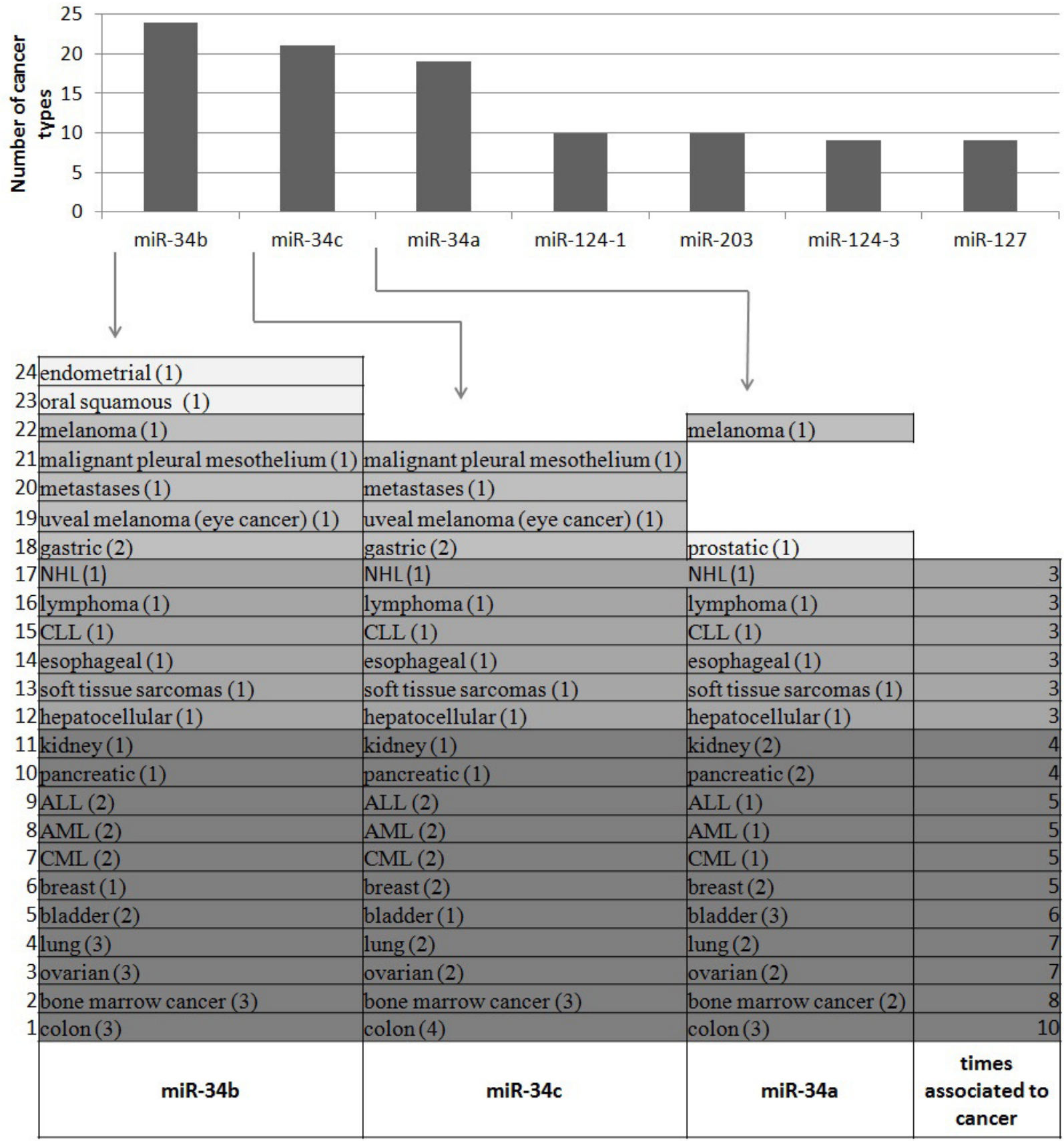

Figure 1: MicroRNA genes shown to be regulated by DNA methylation in more than nine cancer types. The number in bracket represents the number of reports describing the association between miRNA gene that is silenced by DNA methylation and cancer type. The darker the colour, the stronger association between miRNA gene and cancer type. ALL (acute lymphoblastic leukemia), AML (acute myeloid leukemia), CML (chronic myelogenous leukemia), CLL (chronic lymphocytic leukemia), NHL (non-Hodgkin lymphoma). Bone marrow cancer consists of myeloproliferative neoplasms, myeloma and lymphoma.

known human mature miRNA genes, miRNA gene family miR-34 has been found to be regulated by DNA methylation in the highest number of cancer types. Consequently we focused the research on
miR-34 gene family and developed the catalog of cancer types which were shown to be associated with regulation of miR-34 gene family by DNA methylation that is available online. Additionally, 
we also developed the miR-34 gene family regulatory atlas, consisting of its upstream regulators, overlapping genomic elements and downstream targets (transcription factor binding sites (TFBSs), CpG islands, genetic variability, and QTL). Moreover, we discussed potential of miR-34 gene family as biomarker, cure and epigenetic experimental control.

\section{Catalog of cancer types associated with miR-34 silencing by DNA methylation}

We performed an extensive literature mining and collected of 104 papers related with epigenetic silencing of miRNA genes by DNA methylation in cancer. Data integration revealed 158 miRNA genes that have been shown to be deregulated by DNA methylation in 34 different cancer types. Analysis revealed that miR-34 gene family is regulated by DNA methylation in the highest number of cancer types (Figure 1), thus confirming results from our previous integrative study ${ }^{12}$. Out of 104 papers 28 studies described aberrant DNA methylation of miR-34 gene family in 25 cancer types ${ }^{24-52}$. Out of these 28 studies, five were performed at the genome-wide or multi-loci level using microarrays ${ }^{32}$ and quantitative reverse transcription PCR (RT-PCR) ${ }^{27,42,43,49}$, the remaining 23 papers focused on the members of miR-34 family. Figure 1 represents the number of different cancer types that were reported to be associated with miR-34 gene silencing by DNA methylation. MicroRNA-34b was found to be silenced by DNA methylation in 24, $m i R-34 c$ in 21 and $m i R-34 a$ in 19 cancer types. All three members of miR-34 gene family were silenced by DNA methylation in 17 cancer types. MicroRNA-34b and $m i R-34 c$ were additionally silenced by DNA methylation in a set of four cancer types. Moreover miR-34b and miR-34a were silenced by DNA methylation in melanoma. Furthermore miR-34b had been silenced by DNA methylation in oral squamous and endometrial cancer while $m i R-34 a$ had been silenced by DNA methylation in prostatic cancer. Colon cancer was most frequently associated with epigenetic silencing of miR-34 gene family; five studies described ten associations between the miR-34 gene family members and colon cancer ${ }^{24,27,34,40,51}$. Other cancer types have also been frequently linked with miR-34 gene family: bone marrow cancer eight times, ovarian and lung cancer seven times, bladder cancer six times, breast, chronic myelogenous leukemia (CML), acute myeloid leukemia (AML), acute lymphoblastic leukemia (ALL) five times and pancreatic and kidney cancer four times. Moreover, some papers reported that beside DNA methylation histone modifications are additional epigenetic regulators of miR-34 gene family expression ${ }^{32,42}$. Detailed catalog of cancer types which were shown to be associated with regulation of miR-34 gene family by DNA methylation is available online (http://www.integratomics-time.com/epigenetics/ catalog2).

\section{MicroRNA-34 gene family regulatory atlas}

To gain the insight into a miR-34 gene regulation we developed a miR-34 gene family

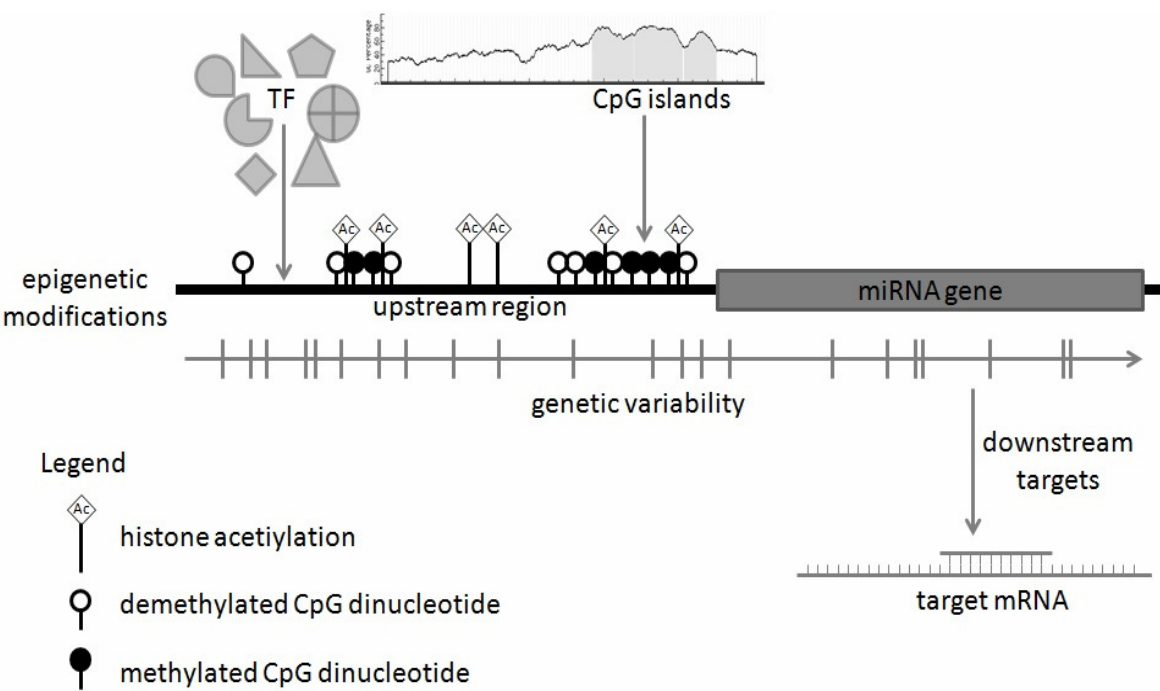

Figure 2: A miR-34 gene family regulatory atlas.

An atlas integrates relevant genomic data regarding DNA methylation, histone modifications, $\mathrm{CpG}$ islands, upstream regulators, downstream targets and genetic variability 


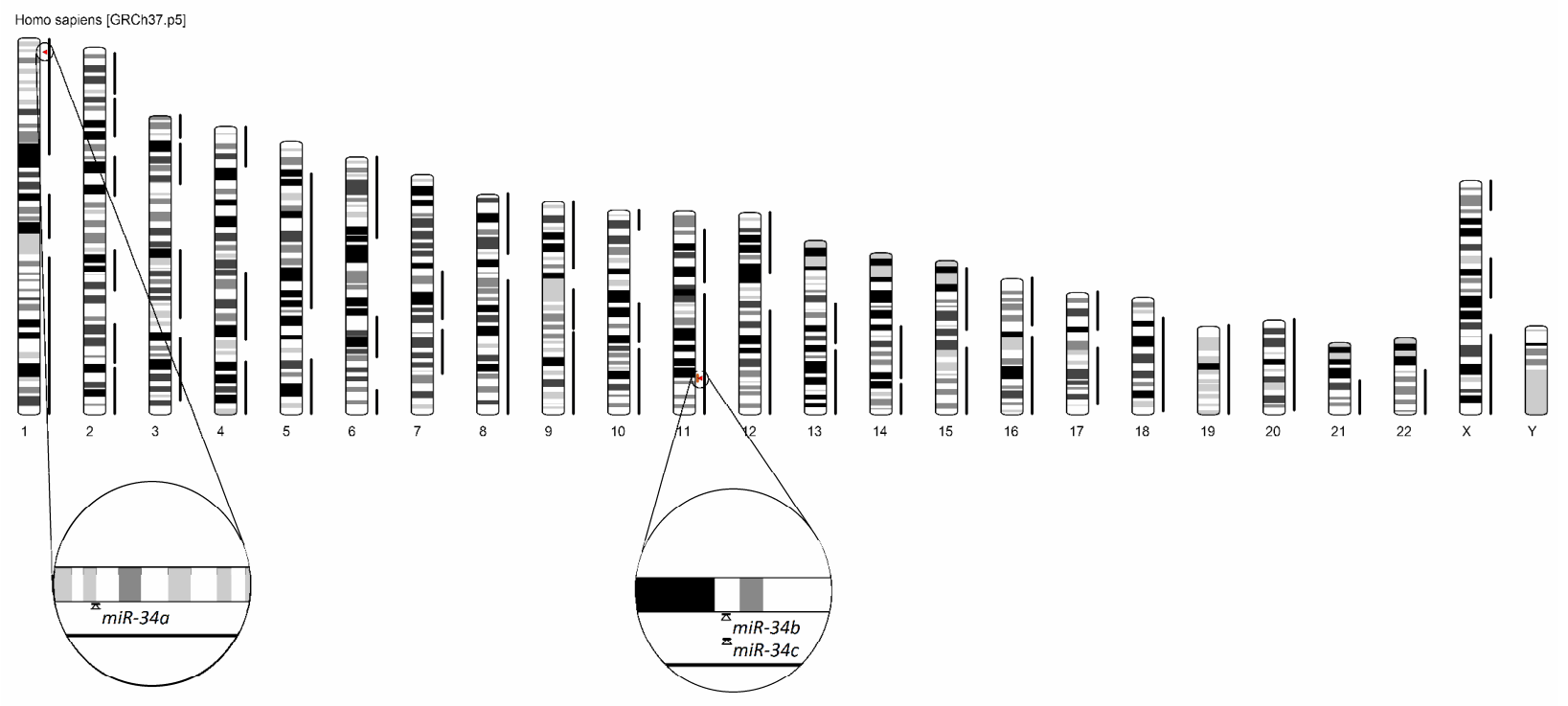

Figure 3: Genomic location of $m i R-34-a,-b$, and $-c$ genes and overlapping QTL. Analysis was performed using miRNA genomic viewer and revealed that all three members of the miR-34 family genes overlapped with QTL for prostatic neoplasms.

regulatory atlas by integrating the following data: 1.upstream regulators (TFBSs, CpG islands), 2.overlapping genetic elements (genetic variability, QTL), and 3. experimentally validated downstream targets (Figure 2).

MicroRNA-34 gene family maps to two chromosomes: 1p36.22 (miR-34a) and 11q23.1 ( $m i R-34 b$ and $m i R-34 c)$ (Figure 3 ). The analysis using the miRNA Genomic Viewer tool revealed that all three miR-34 gene family genes overlap with QTL for prostatic neoplasms and that miR$34 b / c$ overlap with QTL associated with breast neoplasms.

MicroRNA genes $m i R-34 b$ and $m i R-34 c$ are located $494 \mathrm{bp}$ from one another. In silico $\mathrm{CpG}$ analysis revealed that both $m i R-34 a$ and $m i R-34 b / c$ genes are associated with one and three predicted $\mathrm{CpG}$ islands respectively (Figure 4). There is one $\mathrm{CpG}$ island within the $2 \mathrm{~kb}$ upstream region of $m i R$ $34 a$; located $620 \mathrm{bp}$ from the beginning of $m i R-34 a$ gene and comprises $109 \mathrm{bp}$. Three CpG islands are located within $2 \mathrm{~kb}$ upstream region of $m i R-34 b / c$ gene. MicroRNA-34b is imbedded in the second and third $\mathrm{CpG}$ island. Moreover, promoter region of $m i R-34 b / c$ gene is birectional and also drives expression of $\mathrm{BTG} 4^{27}$.

Inquiry using miRNA SNiPer tool showed that pre-miR-34a is polymorphic, as it has one SNP in the seed region of miR-34a-5p and one in the loop of pre-miR-34a ${ }^{17}$. Moreover, the analysis of the SNPs, deposited in the Ensembl database showed that SNPs within the upstream region of the miR-34 overlapped with $\mathrm{CpG}$ dinucleotides and could therefore potentially cause gain or loss of the methylated sites. In the upstream $2 \mathrm{~kb}$ region there are nine and nine SNPs in each; $m i R-34 a$ and $m i R$ $34 \mathrm{~b} / \mathrm{c}$ gene, which are located within $\mathrm{CpG}$ dinucleotides and could cause gain or loss of the $\mathrm{CpG}$ dinucleotides, including one and five SNPs that are located within predicted $\mathrm{CpG}$ islands, respectively.

Additionally, our query at ChIPBase revealed, that there are four common TFBSs present within the $5 \mathrm{~kb}$ upstream regions of the miR-34 gene family (CDX2, FoxA1, HNF4A, and p63), while miR-34a has additional 18 TFBSs within the $5 \mathrm{~kb}$ upstream region. Moreover, miR-34 gene family is a downstream target of $\mathrm{p}^{32,53}$. Comparison of ChIPBase data and genetic variability from Ensembl revealed that within $m i R$ $34 a$ upstream region two SNPs reside within two TFBSs: transcription factor HNF4A binds to $-24 \mathrm{bp}$ (MP_ESP_1_9211861; C>T) and TAF1 binds to 91 bp (rs116877979; A>C).

To collect all known data regarding downstream targets of miR-34 gene family we 

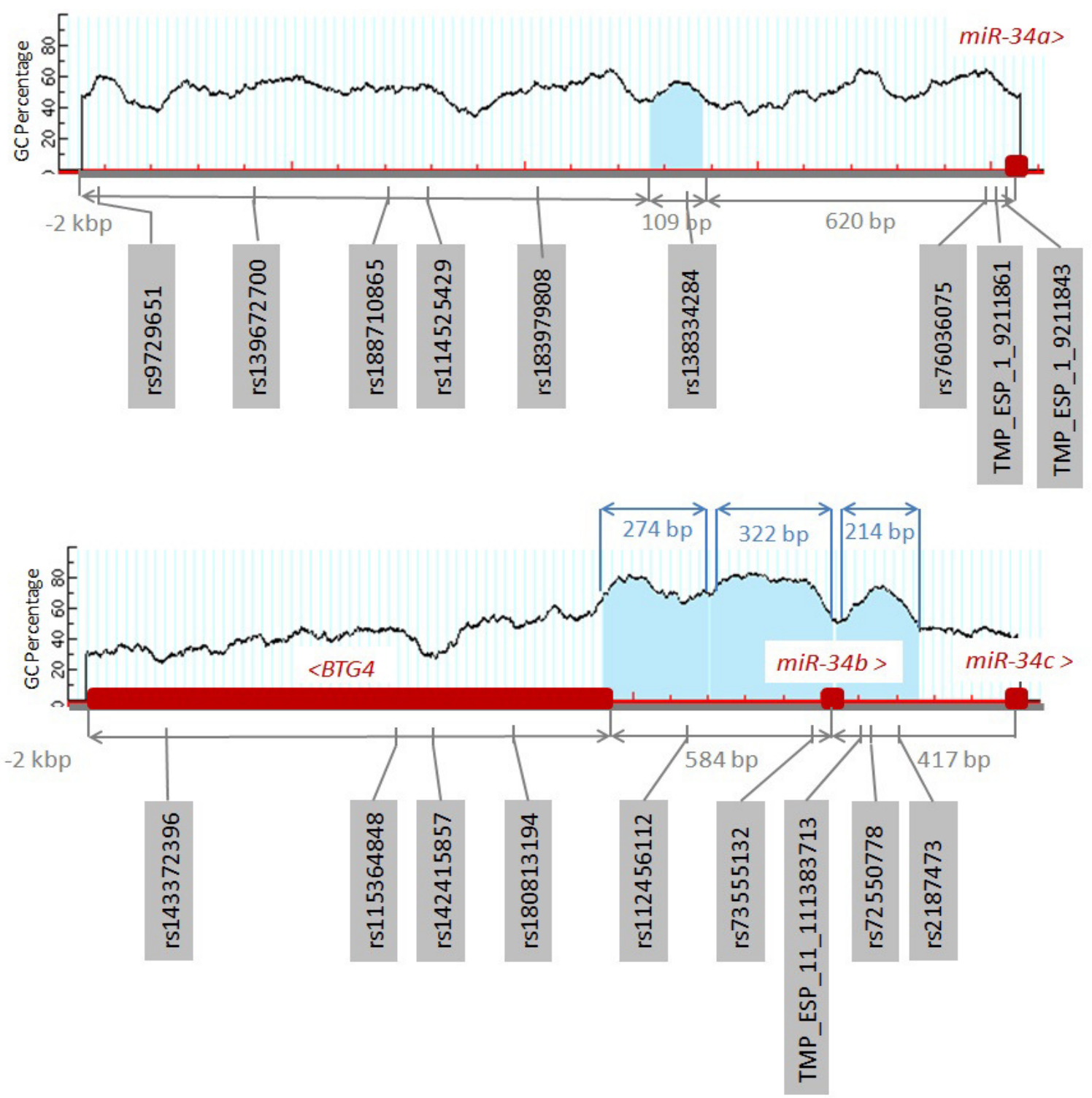

Figure 4: CpG island analysis of miR-34 family and SNPs that could affect gain/loss of DNA methylation sites. One $\mathrm{CpG}$ island is located upstream of the miR-34a gene. Three $\mathrm{CpG}$ islands are located upstream of the $\mathrm{miR}-34 \mathrm{~b} / \mathrm{c}$ gene region and miR-34b is embedded in the $\mathrm{CpG}$ island. Promoter for miR-34b/c is birectional and it also regulates BTG4. Six SNPs overlap CpG dinucleotides within promoter regions: one SNP is located upstream of miR-34a gene and five upstream of the miR-34b/c gene.

integrated data from databases specialized for collecting of experimentally validated miRNA targets (TarBase, miRecords) and the literature ${ }^{24,27,}$ $28,30,34,50,54,55$. The data collection revealed that miR34 family, which has conserved seed regions has several experimentally validated targets (Figure 5): miR-34a, b, and $\mathrm{c}$ have 45, 19 and 16 experimentally validated targets respectively. There are 11 mRNAs targeted by all three members of miR-34 gene family, four mRNAs that are targeted by miR-34b and miR-34c, two mRNAs that are targeted by miR-34a and miR-34b and one mRNA that is targeted by miR-34a and miR-34c. For example, Toyota et al. reported that MET, CCNE2, CDK4, CAV1, MYB, SFRS2 mRNAs are targeted by $\mathrm{miR}-34 \mathrm{~b} / \mathrm{c}$ in colon cancer cell lines and tumors ${ }^{27}$

To analyze if there are other miRNAs which could vicariate the function of miR-34 family, we performed a comparison of all known 
a)

)

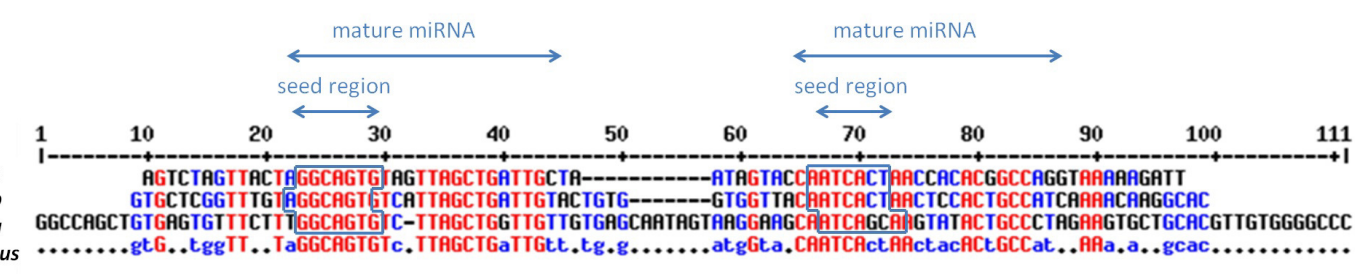

b) Common targets: 8-Catenin, CCNE2 , CDK4, CDK6, E2F2, LRP6, MET, MYC, SNAIL, WNT1, WNT3

b) miR-34a: MAP2K1, AXIN2 , EPHA5, JAG1 , Fra-1, VEGFA, MYB , SIRT6, PDK1, GP1, HK2, HK1, IMPDH, LDHA, SOX2, NANOG, ARHGAP1, AXL, AXIN2, SURVIVIn, SIR T1, PDGFRA, YY1, E2F5, NOTCH , CCND1 , SIRT1 , MYCN , BCL2 ,CD44 , AXL , DLL1 , MTA2, LEF1

miR-34b: C-MET , CAV1, SFRS2, CCNE2, CREB, VEGFA, MYB

miR-34c: C-MET , CAV1, SFRS2, CCNE2, Fra-1

Figure 5: Alignment of the miR-34 family pre-miRNA sequences and experimentally validated targets of the miR-34 gene family. a) Alignment of pre-miRNA sequences of miR-34 gene family. Red nucleotides are present in all three members of miR-34 gene family, blue nucleotides are present in two members of miR-34 gene family. Seed regions are represented in squares. b) Experimentally validated targets of miR-34 family genes.

miRNA seed regions, which are responsible for target binding. Comparison of seed regions between miR-34 family with all known miRNAs revealed that miR-449a and miR-449b have the same seed sequence as miR-34a and miR-34c (GGCAGUG) and miR-449c has the same seed sequence as miR34b (AGGCAGU).

The developed miR-34 gene family regulatory atlas and catalog of cancer types which were shown to be associated with regulation of miR-34 gene family by DNA methylation will further improve our understanding of role of miR34 gene family in cancer.

\section{DISCUSSION}

\section{Catalog of cancer types associated with miR-34} silencing by DNA methylation

Out of all 75 possible combinations of miR-34 family genes $(n=3)$ and 25 analyzed cancer types, scientific papers reported 64 combinations of miR34 family genes and cancer types. Out of these 64 combinations, 26 (40.6\%) have been reported in more than one study thus enabling more reliable confirmation for epigenetic silencing. MicroRNA gene family miR-34 has a potential to be used as general cancer biomarker or as experimental internal control because combination of miR-34a, $m i R-34 b$ and $m i R-34 c$ was silenced by DNA methylation in 25 out of all $35(71.4 \%)$ analyzed cancer types. The majority of researchers used miR127 as internal experimental control as it was the first discovered miRNA to be epigenetically regulated $^{14}$. However, our analysis revealed that miR-127 was deregulated by DNA methylation in nine cancer types, while miR-34 gene family was silenced by DNA methylation in 25 cancer types; thus we are proposing that in the future experiments miR-34 family could be also used as control.

It is very likely that with the upcoming publications the number of cancer types with deregulated miRNA genes by DNA methylation will increase thus revealing which miRNA is more suitable as gold standard. Furthermore the focus of the studies is not evenly distributed across cancer types; colon cancer is one of the most researched cancer types, while oral squamous, prostatic and endometrial cancer have been researched in only one publication. Thus we are proposing decision tree for more efficient planning of the future experiments by the interested scientific community (Figure 6).

\section{MicroRNA-34 gene family regulatory atlas}

According to previous research ${ }^{12}, 20 \%$ of miRNA genes regulated by DNA methylation in cancer had $\mathrm{CpG}$ islands in $5 \mathrm{~kb}$ upstream region and among them $14 \%$ of miRNA genes had CpG islands that overlap with miRNA genes and $m i R-34 b / c$ gene being one of them. It has been previously shown that $m i R-34 b / c$ gene is regulated by a birectional promoter, which is shared with the BTG4 gene $^{27}$. Moreover, the promoter activity in the $m i R-34 b / c$ direction was almost twice that in the BGT4 direction. Furthermore BGT4 also functions as 


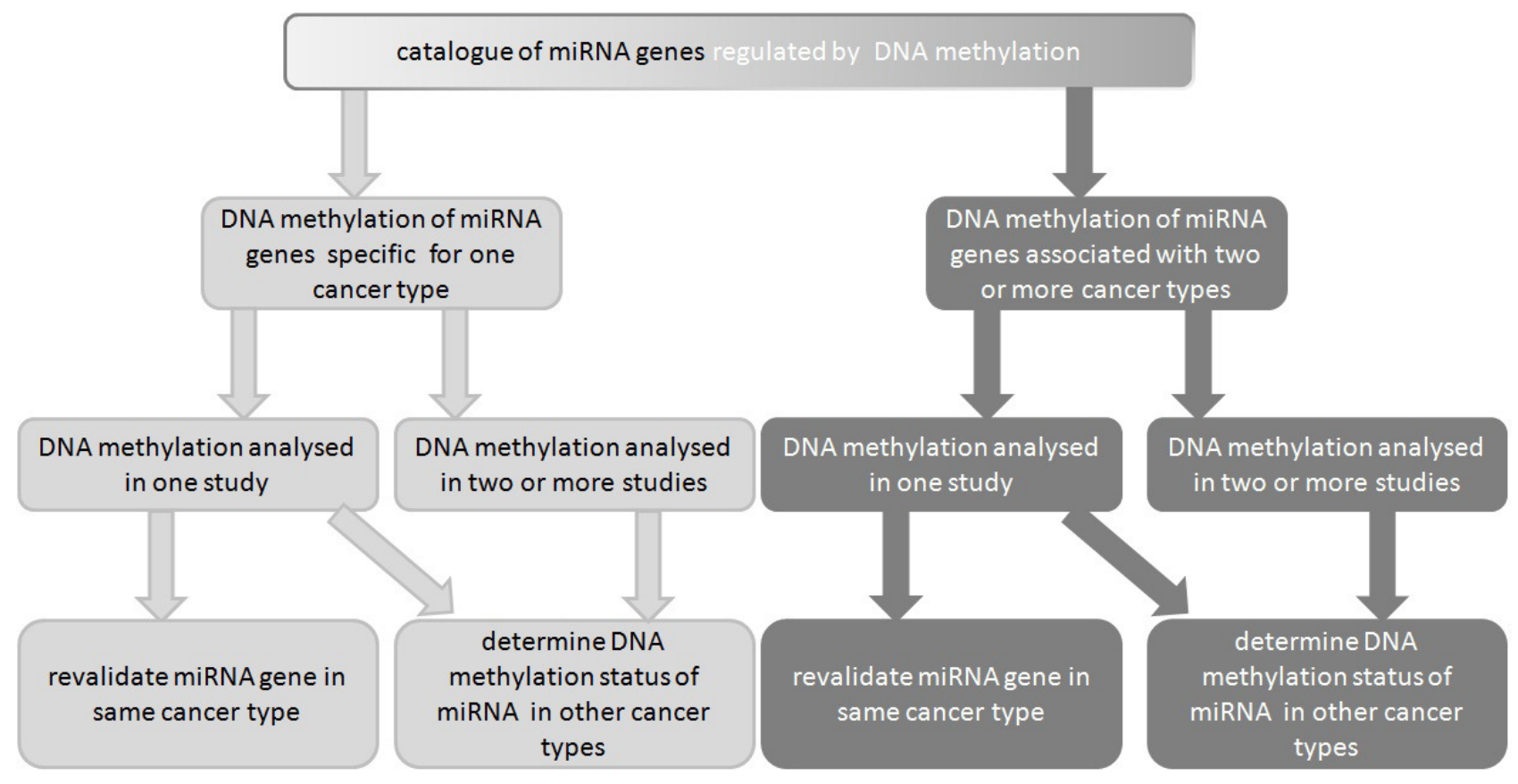

Figure 6: Proposed decision tree for identification of miRNA genes silenced by DNA methylation in cancer.

tumor suppressor as it has anti-proliferative properties and can induce G1 cell cycle arrest. Also miR-34 gene family was reported to be direct p53 target, which induces apoptosis, senescence and cell cycle arrest (reviewed in $^{32}$ ). Welch et al. ${ }^{56}$ reports that $1 \mathrm{q} 36.22$ is frequently deleted in neuroblastoma thus causing down regulation of miR-34a without epigenetic mechanisms. Moreover, there are SNPs present in the $\mathrm{CpG}$ islands upstream of miR-34 gene family genes, some of them might affect gain or loss of the CG dinucleotides thus resulting in another potential source of aberrant methylation thus having biomarker potential. An example of miRNA promoter annotation is presented in Baer et al. ${ }^{57}$ where they discuss the problem of promoter annotation using gene family miR-34 as an example.

As members of miR-34 gene family have conserved seed sequences (Figure 5a), some targets are common for all three members of the miR-34 gene family (Figure $5 \mathrm{~b}$ ); the analysis revealed that 11 mRNAs (MYC, CDK6, E2F3, CDK4, LRP6, WNT3, WNT1, SNAIL, MET, CCNE2 and $\beta$ Catenin) are targeted by all three members of miR34 family. There are also seven genes that are targeted by two of the miR-34 family - C-MET, $C A V 1, S F R S 2, C C N E 2$ are targeted by both miR$34 \mathrm{~b}$ and miR-34c, while VEGFA and $M Y B$ are targeted by miR-34a and miR-34b and Fra- 1 is targeted by both miR-34a and miR-34c. Moreover, recent study indicates that inhibition of $M y c$ in mice kills lung cancer cells ${ }^{58}$, thus making the opportunity to regulate $M Y C$ expression with miR34 family effective and efficient cure for cancer. Similar experiment also identified miR-34a as a potential inhibitor of prostate cancer cells and metastasis by targeting CD $44^{59}$.

Comparison of miRNA seed regions revealed that other miRNA have the same seed sequence as members of miR-34 gene family. Moreover, it has been previously shown that a SNP within seed region could cause the formation of the seed region annotated to a different miRNA ${ }^{17,18}$; therefore there is a possibility that SNPs within seed regions of other miRNA could cause formation of seed region annotated to member of gene family miR-34. However, to our knowledge to date there are no reports of SNPs that would cause formation of miR-34 gene family seed regions. Moreover, SNPs that are located within the transcription factor binding sequence of $m i R-34 a$ could have potential therapeutic value as they could affect expression of miR-34a by gain or loss of transcription binding sites; however the effects of these SNPs on expression of miR-34a have yet to be experimentally tested. The developed atlas could 
- MicroRNA-34 gene family is regulated by DNA methylation in the highest number of analyzed cancer types.

- MicroRNA-34 gene family regulatory atlas integrates relevant data regarding regulation of miR-34 gene family, up- and down-stream targets, single-nucleotide polymorphisms (SNPs), CpG islands and could thus serve as a foundation for future functional research.

$\checkmark$ DNA methylation status of miR-34 gene family has not been determined in all cancer types thus we are proposing a decision tree, based on which future research could be more efficiently organized. MicroRNA mimetics are now in clinical trials for a wide variety of malignancies.

now be complemented with novel discovered regulatory elements.

\section{Cure and biomarker potential}

Reexpression or ectopic expression of one of the members of miR-34 gene family led to inhibition of cellular proliferation and enhancement of apoptosis in myeloma cells ${ }^{44}$, suppression of migration and invasion in prostate cancer cell lines ${ }^{60}$ and reduction in cell invasion, motility and attachment rates in the stage 3 and stage 4 melanoma cell lines ${ }^{43}$. These studies indicate that miR-34 gene family plays an important role in cancer development, invasion and survivability. This combined data suggests that azacitidine (Aza-dC) and other demethylating agents (methyltransferase inhibitors) would be useful treatment for solid tumors. However as demethylating agents are not specific and they demethylate DNA randomly, their side effect may be severe. However, a miR-34 gene family specific demethylating drug or ectopic expression of miR-34 gene family would offer effective cure for cancer with little to no side effects. This concept has already been proven in study ${ }^{61}$ in which transplanted tumors in mice were treated with miR34a mimics and complete inhibition of tumor growth was achieved without any detectable side effects. However, as cancer tissue is composed of many independent subclones this experiment does not fully represent in vivo conditions and effect, but it serves as a proof of concept that miR-34 gene family has cure potential that has to be researched and proven extensively in the future studies. First breakthrough has already been achieved as a drug with MRX34 entered Stage I in April 2013 $\left(\right.$ reviewed $\mathrm{in}^{55}$ ). Moreover the potential of miRNA and long non-coding RNA (lncRNA) for treatment of cancer has already been recognized and is the topic of increasing research (discussed in ${ }^{62}$ ).

Specific biomarker potential for miR-34 gene family has already been recognized in other scientific papers, but no scientific paper reports miR-34 gene family as general cancer biomarker. A lot of scientific papers are proposing that members of miR-34 gene family could be used as biomarker for specific cancer type - but we are proposing miR34 gene family should be used as a general cancer biomarker, as it has been found to be silenced by DNA methylation in 25 cancer types $^{37,42}$. Moreover, miR-34 gene family's DNA methylation was found to be cancer cells specific, as normal tissue has demethylated $\mathrm{CpG}$ islands, while cancer cells have aberrant CpG DNA methylation ${ }^{27-30,32,39,44}$. As biomarker and therapeutic development is multistage and highly complex procedure it can be aided and facilitated by integrative projects such as Integratomics TIME (http://www.integratomicstime.com/home).

\section{CONCLUSIONS}

In conclusion, our systematic data integration and bioinformatics analysis revealed that miR-34 family could be used as a general cancer biomarker because miR-34 family is silenced by DNA methylation in a high number of cancer types. Furthermore our and other studies conducted on the topic of epigenetic regulation of miR-34 gene family indicate that miR-34 gene family is a master regulator of tumor biology. Moreover, in comparison to protein-coding genes miRNA offer better biomarker properties as the frequency of miRNA gene DNA methylation is an order of magnitude higher. We are also proposing that the 
researchers could use miR-34 gene family as experimental internal control in epigenetic studies. But still more preclinical studies related with miR34 gene family need to be conducted in order to better characterize its regulation and its downstream molecular pathways. Furthermore researchers should focus on combinations of miR-34 family genes and cancer types that have not already been proven to be silenced by DNA methylation as proposed by decision tree. Therefore the supplemented catalog available at http://www.integratomics-time.com/epigenetics/ catalog2 and the miR-34 gene family regulatory atlas presented in this study provide a starting point for further analyses and could thus facilitate development of therapeutics.

\section{Acknowledgements}

This work was supported by the Slovenian Research Agency (ARRS) through the Research programme Comparative genomics and genome biodiversity (P4-0220).

\section{Conflict of Interest}

The authors do not declare any conflict of interest.

\section{References:}

1. Friedman RC, Farh KK, Burge CB, Bartel DP. Most mammalian mRNAs are conserved targets of microRNAs. Genome Res. 2009 Jan; 19(1): 92-105.

2. Kunej T, Godnic I, Horvat S, Zorc M, Calin GA. Cross talk between microRNA and coding cancer genes. Cancer J. 20122012 May-Jun; 18(3): 223231.

3. Calin GA, Sevignani C, Dumitru CD, Hyslop T, Noch E, Yendamuri S, et al. Human microRNA genes are frequently located at fragile sites and genomic regions involved in cancers. Proc Natl Acad Sci U S A. 2004 Mar; 101(9): 2999-3004.

4. Brennecke J, Hipfner DR, Stark A, Russell RB, Cohen SM. bantam encodes a developmentally regulated microRNA that controls cell proliferation and regulates the proapoptotic gene hid in Drosophila. Cell 2003 Apr; 113(1): 25-36.

5. Lee RC, Feinbaum RL, Ambros V. The C. elegans heterochronic gene lin-4 encodes small RNAs with antisense complementarity to lin-14. Cell 1993 Dec; 75(5): 843-854.

6. Calin GA, Croce CM. MicroRNA signatures in human cancers. Nat Rev Cancer 2006 Nov; 6(11): 857-866.

7. Gaur A, Jewell DA, Liang Y, Ridzon D, Moore JH, Chen $\mathrm{C}$, et al. Characterization of microRNA expression levels and their biological correlates in human cancer cell lines. Cancer Res. 2007 Mar; 67(6): 2456-2468.

8. Lu C, Tej SS, Luo S, Haudenschild CD, Meyers BC, Green PJ. Elucidation of the small RNA component of the transcriptome. Science 2005 Sep; 309(5740): 1567-1569.

9. Fabbri M, Ivan M, Cimmino A, Negrini M, Calin GA. Regulatory mechanisms of microRNAs involvement in cancer. Expert Opin Biol Ther. 2007 Jul; 7(7): 1009-1019.

10. Agostini M, Knight RA. miR-34: from bench to bedside. Oncotarget 2014 Mar; 5(4): 872-881.

11. Ferdin J, Kunej T, Calin GA. Non-coding RNAs: identification of cancer-associated microRNAs by gene profiling. Technol Cancer Res Treat. 2010 Apr; 9(2): 123-138.

12. Kunej T, Godnic I, Ferdin J, Horvat S, Dovc P, Calin GA. Epigenetic regulation of microRNAs in cancer: an integrated review of literature. Mutat Res. 2011 Dec; 717(1-2): 77-84.

13. Weber B, Stresemann C, Brueckner B, Lyko F. Methylation of human microRNA genes in normal and neoplastic cells. Cell Cycle 2007 May; 6(9): 1001-1005.

14. Saito Y, Liang G, Egger G, Friedman JM, Chuang $\mathrm{JC}$, Coetzee GA, et al. Specific activation of microRNA-127 with downregulation of the protooncogene BCL6 by chromatin-modifying drugs in human cancer cells. Cancer Cell 2006 Jun; 9(6): 435-443.

15. Kozomara A, Griffiths-Jones S. miRBase: integrating microRNA annotation and deepsequencing data. Nucleic Acids Res. 2011 Jan; 39(Database issue): D152-157.

16. Li LC, Dahiya R. MethPrimer: designing primers for methylation PCRs. Bioinformatics 2002 Nov; 18(11): 1427-1431.

17. Zorc M, Skok DJ, Godnic I, Calin GA, Horvat S, Jiang Z, et al. Catalog of microRNA seed polymorphisms in vertebrates. PLoS One 2012; 7(1): e30737.

18. Jevsinek Skok D, Godnic I, Zorc M, Horvat S, Dovc $\mathrm{P}$, Kovac M, et al. Genome-wide in silico screening for microRNA genetic variability in livestock species. Anim Genet 2013 Jul.

19. Lewis BP, Burge CB, Bartel DP. Conserved seed pairing, often flanked by adenosines, indicates that thousands of human genes are microRNA targets. Cell 2005 Jan; 120(1): 15-20.

20. Yang JH, Li JH, Jiang S, Zhou H, Qu LH. ChIPBase: a database for decoding the transcriptional regulation of long non-coding RNA and microRNA genes from ChIP-Seq data. Nucleic Acids Res 2013 Jan; 41(Database issue): D177-187.

21. Sethupathy P, Corda B, Hatzigeorgiou AG. TarBase: A comprehensive database of experimentally 
supported animal microRNA targets. RNA 2006 Feb; 12(2): 192-197.

22. Xiao F, Zuo Z, Cai G, Kang S, Gao X, Li T. miRecords: an integrated resource for microRNAtarget interactions. Nucleic Acids Res. 2009 Jan; 37(Database issue): D105-110.

23. Corpet F. Multiple sequence alignment with hierarchical clustering. Nucleic Acids Res. 1988 Nov; 16(22): 10881-10890.

24. Lodygin D, Tarasov V, Epanchintsev A, Berking C, Knyazeva $\mathrm{T}$, Körner $\mathrm{H}$, et al. Inactivation of miR$34 \mathrm{a}$ by aberrant $\mathrm{CpG}$ methylation in multiple types of cancer. Cell Cycle 2008 Aug; 7(16): 2591-2600.

25. Kozaki K, Imoto I, Mogi S, Omura K, Inazawa J. Exploration of tumor-suppressive microRNAs silenced by DNA hypermethylation in oral cancer. Cancer Res 2008 Apr; 68(7): 2094-2105.

26. Zhang L, Volinia S, Bonome T, Calin GA, Greshock $\mathrm{J}$, Yang $\mathrm{N}$, et al. Genomic and epigenetic alterations deregulate microRNA expression in human epithelial ovarian cancer. Proc Natl Acad Sci U S A 2008 May; 105(19): 7004-7009.

27. Toyota M, Suzuki H, Sasaki Y, Maruyama R, Imai $\mathrm{K}$, Shinomura $\mathrm{Y}$, et al. Epigenetic silencing of microRNA-34b/c and B-cell translocation gene 4 is associated with $\mathrm{CpG}$ island methylation in colorectal cancer. Cancer Res 2008 Jun; 68(11): 4123-4132.

28. Lujambio A, Calin GA, Villanueva A, Ropero S, Sánchez-Céspedes M, Blanco D, et al. A microRNA DNA methylation signature for human cancer metastasis. Proceedings of the National Academy of Sciences 2008; 105(36): 13556-13561.

29. Roman-Gomez J, Agirre X, Jiménez-Velasco A, Arqueros V, Vilas-Zornoza A, Rodriguez-Otero P, et al. Epigenetic Regulation of MicroRNAs in Acute Lymphoblastic Leukemia. Journal of Clinical Oncology 2009; 27(8): 1316-1322.

30. Pigazzi M, Manara E, Baron E, Basso G. miR-34b targets cyclic AMP-responsive element binding protein in acute myeloid leukemia. Cancer Res. 2009 Mar; 69(6): 2471-2478.

31. Corney DC, Hwang CI, Matoso A, Vogt M, Flesken-Nikitin A, Godwin AK, et al. Frequent downregulation of miR-34 family in human ovarian cancers. Clin Cancer Res. 2010 Feb; 16(4): 11191128.

32. Suzuki H, Yamamoto E, Nojima M, Kai M, Yamano $\mathrm{HO}$, Yoshikawa $\mathrm{K}$, et al. Methylation-associated silencing of microRNA-34b/c in gastric cancer and its involvement in an epigenetic field defect. Carcinogenesis 2010 Dec; 31(12): 2066-2073.

33. Dudziec E, Miah S, Choudhry HM, Owen HC, Blizard S, Glover M, et al. Hypermethylation of $\mathrm{CpG}$ islands and shores around specific microRNAs and mirtrons is associated with the phenotype and presence of bladder cancer. Clin Cancer Res. 2011 Mar; 17(6): 1287-1296.

34. Vogt M, Munding J, Grüner M, Liffers ST, Verdoodt B, Hauk J, et al. Frequent concomitant inactivation of miR-34a and $\mathrm{miR}-34 \mathrm{~b} / \mathrm{c}$ by $\mathrm{CpG}$ methylation in colorectal, pancreatic, mammary, ovarian, urothelial, and renal cell carcinomas and soft tissue sarcomas. Virchows Arch. 2011 Mar; 458(3): 313-322.

35. Chim CS, Wong KY, Qi Y, Loong F, Lam WL, Wong LG, et al. Epigenetic inactivation of the miR$34 \mathrm{a}$ in hematological malignancies. Carcinogenesis 2010; 31(4): 745-750.

36. Chim CS, Wong KY, Leung CY, Chung LP, Hui $\mathrm{PK}$, Chan SY, et al. Epigenetic inactivation of the hsa-miR-203 in haematological malignancies. J Cell Mol Med. 2011 Dec; 15(12): 2760-2767.

37. Wang Z, Chen Z, Gao Y, Li N, Li B, Tan F, et al. DNA hypermethylation of microRNA-34b/c has prognostic value for stage I non-small cell lung cancer. Cancer Biol Ther. 2011 Mar; 11(5): 490496.

38. Botezatu A, Goia-Rusanu CD, Iancu IV, Huica I, Plesa A, Socolov D, et al. Quantitative analysis of the relationship between microRNA-124a, -34b and -203 gene methylation and cervical oncogenesis. Mol Med Report 20112011 Jan-Feb; 4(1): 121-128.

39. Chen X, Hu H, Guan X, Xiong G, Wang Y, Wang $\mathrm{K}$, et al. $\mathrm{CpG}$ island methylation status of miRNAs in esophageal squamous cell carcinoma. Int $J$ Cancer 2012 Apr; 130(7): 1607-1613.

40. Kalimutho M, Di Cecilia S, Del Vecchio Blanco G, Roviello F, Sileri P, Cretella M, et al. Epigenetically silenced $\mathrm{miR}-34 \mathrm{~b} / \mathrm{c}$ as a novel faecal-based screening marker for colorectal cancer. Br J Cancer 2011 May; 104(11): 1770-1778.

41. Kubo T, Toyooka S, Tsukuda K, Sakaguchi M, Fukazawa T, Soh J, et al. Epigenetic silencing of microRNA-34b/c plays an important role in the pathogenesis of malignant pleural mesothelioma. Clin Cancer Res. 2011 Aug; 17(15): 4965-4974.

42. Watanabe K, Emoto N, Hamano E, Sunohara M, Kawakami M, Kage $\mathrm{H}$, et al. Genome structurebased screening identified epigenetically silenced microRNA associated with invasiveness in nonsmall-cell lung cancer. Int J Cancer 2012 Jun; 130(11): 2580-2590.

43. Mazar J, Khaitan D, DeBlasio D, Zhong C, Govindarajan SS, Kopanathi S, et al. Epigenetic regulation of microRNA genes and the role of miR$34 \mathrm{~b}$ in cell invasion and motility in human melanoma. PLoS One 2011; 6(9): e24922.

44. Wong KY, Yim RL, So CC, Jin DY, Liang R, Chim CS. Epigenetic inactivation of the MIR34B/C in multiple myeloma. Blood 2011 Nov; 118(22): 59015904. 
45. Tanaka N, Toyooka S, Soh J, Kubo T, Yamamoto H, Maki Y, et al. Frequent methylation and oncogenic role of microRNA-34b/c in small-cell lung cancer. Lung Cancer 2012 Apr; 76(1): 32-38.

46. Hiroki E, Suzuki F, Akahira J, Nagase S, Ito K, Sugawara J, et al. MicroRNA-34b functions as a potential tumor suppressor in endometrial serous adenocarcinoma. Int J Cancer 2012 Aug; 131(4): E395-404.

47. Yu F, Jiao Y, Zhu Y, Wang Y, Zhu J, Cui X, et al. MicroRNA 34c gene down-regulation via DNA methylation promotes self-renewal and epithelialmesenchymal transition in breast tumor-initiating cells. J Biol Chem 2012 Jan; 287(1): 465-473.

48. Tsai K-W, Kao H-W, Chen H-C, Chen S-J, Lin W-c. Epigenetic control of the expression of a primatespecific microRNA cluster in human cancer cells. Epigenetics 2009; 4(8): 587-592.

49. Tsai KW, Wu CW, Hu LY, Li SC, Liao YL, Lai $\mathrm{CH}$, et al. Epigenetic regulation of miR-34b and miR-129 expression in gastric cancer. Int J Cancer 2011 Dec; 129(11): 2600-2610.

50. Dong F, Lou D. MicroRNA-34b/c suppresses uveal melanoma cell proliferation and migration through multiple targets. Mol Vis. 2012; 18: 537-546.

51. Roy S, Levi E, Majumdar AP, Sarkar FH. Expression of miR-34 is lost in colon cancer which can be re-expressed by a novel agent CDF. $J$ Hematol Oncol. 2012; 5: 58.

52. Xie K, Liu J, Chen J, Dong J, Ma H, Liu Y, et al. Methylation-associated silencing of microRNA-34b in hepatocellular carcinoma cancer. Gene 2014 Jun; 543(1): 101-107.

53. He L, He X, Lim LP, de Stanchina E, Xuan Z, Liang $\mathrm{Y}$, et al. A microRNA component of the p53 tumour suppressor network. Nature 2007 Jun; 447(7148): 1130-1134.

54. Chim CS, Wan TS, Wong KY, Fung TK, Drexler $\mathrm{HG}$, Wong KF. Methylation of miR-34a, miR-34b/c, miR-124-1 and miR-203 in Ph-negative myeloproliferative neoplasms. J Transl Med. 2011; 9: 197.
55. Agostini M, Knight RA. miR-34: from bench to bedside. Oncotarget 2014 Mar.

56. Welch C, Chen Y, Stallings RL. MicroRNA-34a functions as a potential tumor suppressor by inducing apoptosis in neuroblastoma cells. Oncogene 2007 Jul; 26(34): 5017-5022.

57. Baer C, Claus R, Plass C. Genome-Wide Epigenetic Regulation of miRNAs in Cancer. Cancer Res. 2013 Jan; 73(2): 473-477.

58. Soucek L, Whitfield J, Martins CP, Finch AJ, Murphy DJ, Sodir NM, et al. Modelling Myc inhibition as a cancer therapy. Nature 2008 Oct; 455(7213): 679-683.

59. Liu C, Kelnar K, Liu B, Chen X, Calhoun-Davis T, $\mathrm{Li} \mathrm{H}$, et al. The microRNA miR-34a inhibits prostate cancer stem cells and metastasis by directly repressing CD44. Nat Med. 2011 Feb; 17(2): 211215.

60. Hagman Z, Larne O, Edsjö A, Bjartell A, Ehrnström RA, Ulmert D, et al. miR-34c is downregulated in prostate cancer and exerts tumor suppressive functions. Int J Cancer 2010 Dec; 127(12): 27682776.

61. Wiggins JF, Ruffino L, Kelnar K, Omotola M, Patrawala L, Brown D, et al. Development of a lung cancer therapeutic based on the tumor suppressor microRNA-34. Cancer Res. 2010 Jul; 70(14): 59235930.

62. Ling H, Fabbri M, Calin GA. MicroRNAs and other non-coding RNAs as targets for anticancer drug development. Nat Rev Drug Discov. 2013 Nov; 12(11): 847-865.

63. Hogan NM, Joyce MR, Kerin MJ. MicroRNA expression in colorectal cancer. Cancer Biomark. 2012; 11(6): 239-243.

DISCOVERIES is a peer-reviewed, open access, online, multidisciplinary and integrative journal, publishing high impact and innovative manuscripts from all areas related to MEDICINE, BIOLOGY and CHEMISTRY; (C) 2014, Applied Systems 